\title{
REVISED Age-specific acceleration in malignant melanoma
}

\section{[version 2; peer review: 2 approved]}

\author{
Brian L Diffey ${ }^{1}$, Steven A Frank ${ }^{2}$ \\ ${ }^{1}$ Dermatological Sciences, Institute of Cellular Medicine, Newcastle University, Newcastle upon Tyne, UK \\ ${ }^{2}$ Department of Ecology and Evolutionary Biology, University of California, Irvine, USA
}

V2 First published: 09 Jan 2017, 6:27
https://doi.org/10.12688/f1000research.10491.1

Latest published: 24 Feb 2017, 6:27

https://doi.org/10.12688/f1000research.10491.2

\begin{abstract}
Background: The overall incidence of melanoma has increased steadily for several years. The relative change in incidence at different ages has not been fully described. Objective: To describe how incidence at different ages has changed over time and to consider what aspects of tumour biology may explain the observed pattern of change in incidence. Methods: The slope of incidence vs age measures the acceleration of cancer incidence with age. We described the pattern of change over time in the overall incidence of melanoma, as well as in acceleration. We used data for males and females from 3 different countries in the 17 sequential 5-year birth-cohort categories from 1895-99 to 1975-79, from which we derived the incidence patterns. Results: Over time, there has been a tendency for the overall incidence of melanoma to increase and for the acceleration (slope) of the age-incidence curves to decline. The changing patterns of melanoma incidence and acceleration differ between males and females and between the countries analysed. Conclusions: The observed pattern in melanoma of rising incidence and declining acceleration occurs in other cancers in response to genetic knockouts of mechanisms that protect against cancer. Perhaps some protective mechanism with respect to melanoma may be less effective now than in the past, possibly because of more intense environmental challenges.
\end{abstract}

\section{Keywords}

melanoma epidemiology, age-period-cohort effects, sun exposure , age-specific incidence

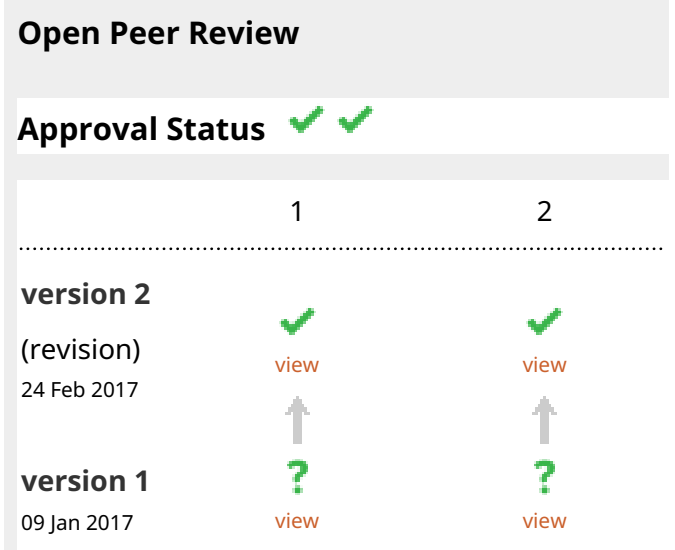

\footnotetext{
1. Antony Young, King's College London, London, UK
2. Robert J. Noble , ETH Zurich, Basel, Switzerland

Any reports and responses or comments on the article can be found at the end of the article.
} 
Corresponding author: Steven A Frank (safrank@uci.edu)

Competing interests: No competing interests were disclosed.

Grant information: This work was supported by National Science Foundation (USA) grant DEB-1251035 to SAF.

The funders had no role in study design, data collection and analysis, decision to publish, or preparation of the manuscript.

Copyright: @ 2017 Diffey BL and Frank SA. This is an open access article distributed under the terms of the Creative Commons

Attribution License, which permits unrestricted use, distribution, and reproduction in any medium, provided the original work is properly cited. Data associated with the article are available under the terms of the Creative Commons Zero "No rights reserved" data waiver (CC0 1.0 Public domain dedication).

How to cite this article: Diffey BL and Frank SA. Age-specific acceleration in malignant melanoma [version 2; peer review: 2 approved] F1000Research 2017, 6:27 https://doi.org/10.12688/f1000research.10491.2

First published: 09 Jan 2017, 6:27 https://doi.org/10.12688/f1000research.10491.1 


\section{REVISED Amendments from Version 1}

The main emphasis continues to be the interesting pattern of rising incidence and declining acceleration of age-specific incidence with respect to year of cohort birth. This version reduces discussion of possible mechanistic causes of the observed patterns. At present, the explanation for the observed patterns remains unknown and poses an interesting challenge for future work.

See referee reports

\section{Introduction}

The incidence of malignant melanoma has increased steadily over the past 50 years in predominately fair-skinned populations ${ }^{1}$. The trends in incidence probably reflect changing prevalence of risk factors such as increased leisure time in sunny destinations, changing fashion and sunbed use, coupled with increased surveillance, early detection and changes in diagnostic criteria ${ }^{2,3}$.

The purpose of this paper is to study the particular ways in which incidence has changed over time. By analysing the 17 sequential 5-year birth cohorts from 1895-99 to 1975-79, we show that incidence has indeed increased steadily over time. Our analysis also shows that the particular patterns of increase in incidence differ between males and females and between different countries.

In addition to the overall increase in incidence, the relationship between age and incidence has also changed over time. We show that more recent cohorts typically have a disproportionate increase in cases at earlier ages.

To quantify the age-incidence relationship and its change over time, we study the rate of change of melanoma incidence with age ${ }^{4-6}$, which is the acceleration of cancer ${ }^{7}$. The patterns of acceleration provide interesting information about the forces acting on cancer progression at different ages ${ }^{8}$.

\section{Methods}

Age-specific incidence data on malignant melanoma (ICD-10; C43) for males and females were obtained for Great Britain ${ }^{9-11}$ for the period 1975-2014, the USA ${ }^{12}$ for the period 1975-2013 and Australia $^{13}$ for the period 1982-2012. Incidence data for the USA relate to white people only.

Because the incidence of melanoma is increasing over time, agespecific rates are heavily influenced by the year of birth. To allow for this effect, we separated the 17 sequential 5-year birth-cohort categories from 1895-99 to 1975-79. For each cohort, we computed the 5-year average age-specific incidences for males and females aged 25 years and over.

The analyses were done with Microsoft Excel 2003.

\section{Results}

Table 1 shows the age-specific incidence for British males born during different time periods. The risk of malignant melanoma within each cohort rises consistently throughout life, as is true for most other cancers ${ }^{8}$. Figure 1 shows the age-incidence curves for both genders from Great Britain, the USA, and Australia for successive birth cohorts from 1895-99 to 1975-79.

From Figure 1, it appears that, over time, there has been a tendency for the acceleration (slope) of the incidence curves to decline. The decline in acceleration over time seems particularly strong for certain datasets shown in Figure 1, for example, for British males. Other datasets, such as Australian females, seem not to show a clear trend. Thus, it is helpful to make a more direct analysis for the changing acceleration patterns between the different datasets.

To describe the tendency for age-specific acceleration to decline over birth cohorts, we calculated the following summary statistics separately for each of the 6 datasets represented by the 6 panels in Figure 2. In each successive pair of the 17 cohorts, we used data only for the common ages shared by the two cohorts. For those common ages, we estimated by linear regression the slope of the $\log$-log age-incidence data, which estimates the age-specific acceleration. We then calculated the ratio of the accelerations for the more recent cohort relative to the prior cohort, and used the logarithm base 2 value of that ratio. A negative value means the more recent cohort has a lower slope.

The average of the logarithms over the successive pairs of cohorts describes the geometric mean of the slopes, capturing the multiplicative tendency of the slope to change over cohorts. A negative value expresses an overall tendency for the slope to decline over time.

To gain a sense of the trend in acceleration over the successive cohorts, Table 2 shows, for each of the 6 datasets, the average logarithm for the ratio of successive slopes, and the standard error of that average. We also calculated the average logarithm divided by the standard error of that average, which gives the deviation from zero in terms of the number of standard errors of the mean.

The overall trends suggest that acceleration has declined over time, consistent with the general visual pattern shown in Figure 2. However, Table 2 shows that there is significant variation in the trends between genders and countries, also apparent from Figure 1 and Figure 2.

In every case the overall tendency over the cohorts has been for incidence to increase and acceleration (slope) to decline.

Dataset 1. Summary data for Figure 1, age-specific incidence of melanoma in different time periods and different countries

http://dx.doi.org/10.5256/f1000research.10491.d148748

Dataset 2. Raw age-specific incidence data for Australia for different age groups in different years

http://dx.doi.org/10.5256/f1000research.10491.d148749

Data obtained from Australian Institute of Health and Welfare (AlHW) 2016, Australian Cancer Incidence and Mortality (ACIM) books: Melanoma of the skin, Canberra: AlHW. Available at http:// www.aihw.gov.au/acim-books. 


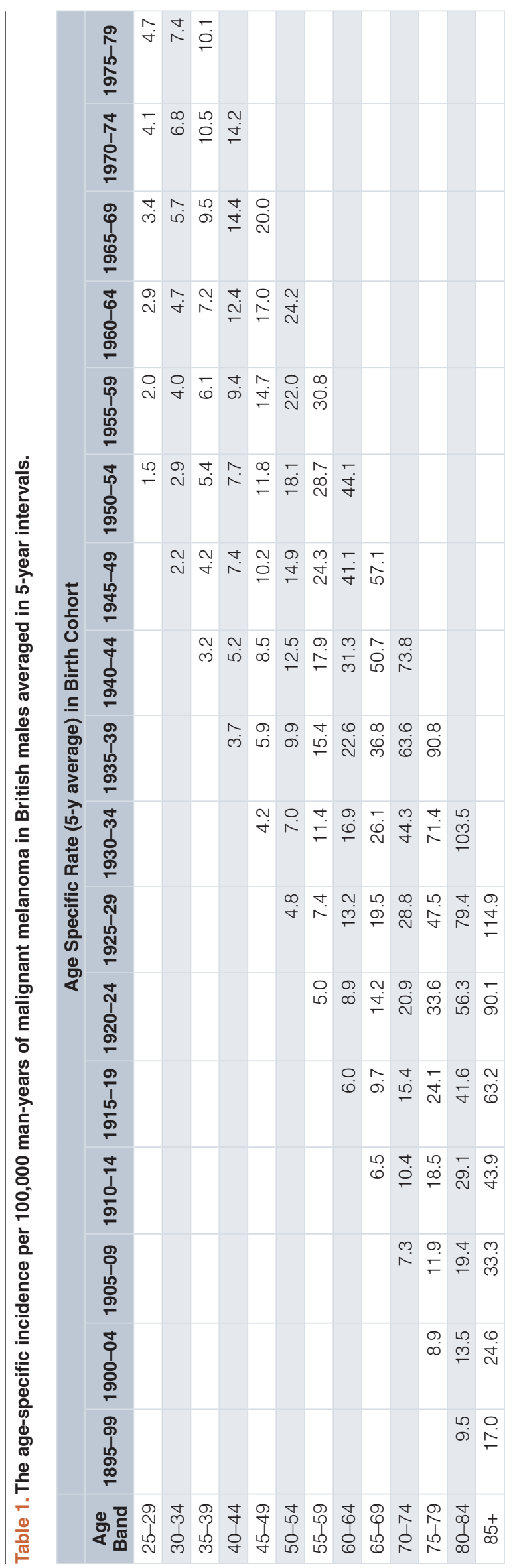



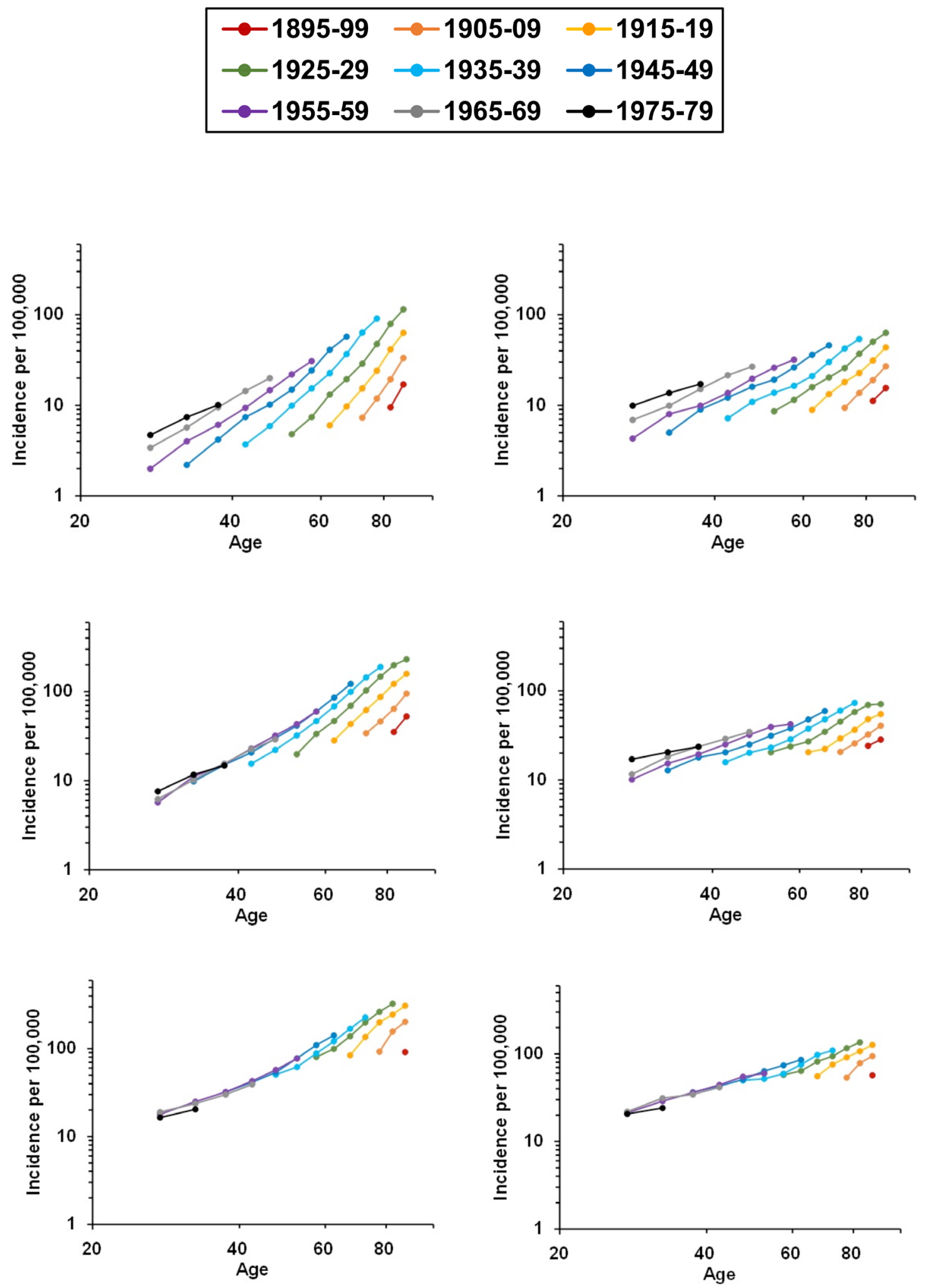

Figure 1. The age-specific incidence of melanoma in different time periods and different countries. The plots show the incidence for males (left) and females (right) in Great Britain (top row), USA (middle row), and Australia (bottom row) for the birth cohorts shown in the top legend. The plots do not show the intermediate decadal cohorts because of visual limitations in plotting the data. The plots are based on the summary given in Dataset 1, derived from the data and analyses in Dataset 2-Dataset 5. Both axes are scaled logarithmically. 


\begin{tabular}{l}
$\rightarrow 1905-09 \rightarrow 1915-19 \rightarrow 1925-29 \rightarrow 1935-39$ \\
$\multimap 1945-49 \rightarrow 1955-59 \rightarrow 1965-69 \rightarrow 1975-79$ \\
\hline
\end{tabular}
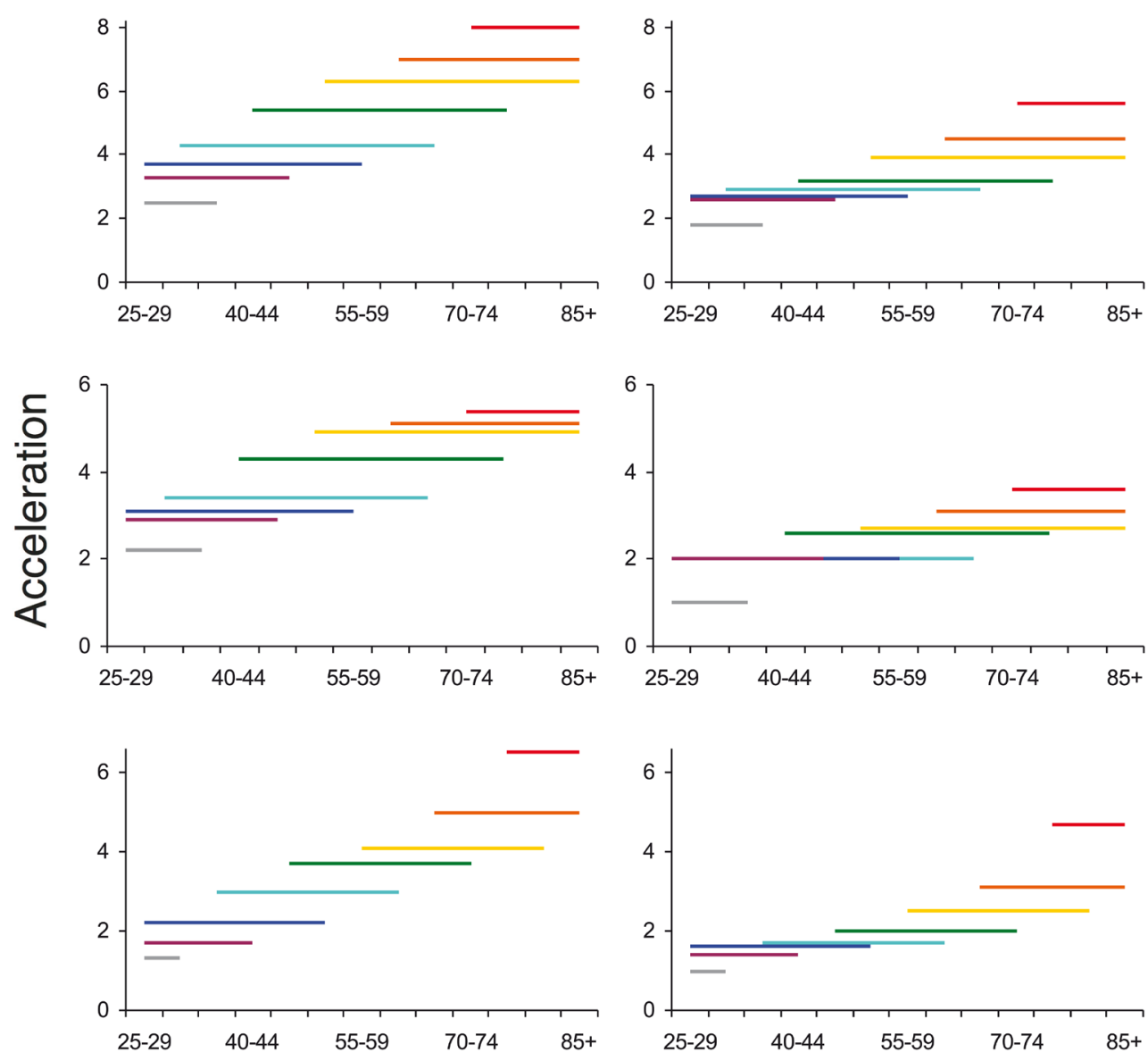

Age band

Figure 2. The age-specific acceleration of melanoma in different time periods and different countries. The plots show the acceleration for males (left) and females (right) in Great Britain (top row), USA (middle row), and Australia (bottom row) for the birth cohorts shown in the top legend. The plots do not show the intermediate decadal cohorts because of visual limitations in plotting the data. The plots are based on the summary given in Dataset 6, derived from the data and analyses in Dataset 2-Dataset 5.

Dataset 3. Raw age-specific incidence data for Great Britain for different age groups in different years

http://dx.doi.org/10.5256/f1000research.10491.d148750

Data obtained from (1) Office for National Statistics,

Cancer Registration Statistics, England, available at

http://www.ons.gov.uk/peoplepopulationandcommunity/

healthandsocialcare/conditionsanddiseases/datasets/

cancerregistrationstatisticscancerregistrationstatisticsengland,

(2) Welsh Cancer Intelligence and Surveillance Unit, Cancer in

Wales, available at: http://www.wcisu.wales.nhs.uk/cancer-in-wales-1, and (3) Information and Statistics Division Scotland, Cancer

Statistics, available at: http://www.isdscotland.org/Health-Topics/

Cancer/Cancer-Statistics/Skin/
Dataset 4. Raw age-specific incidence data for USA for different age groups in different years

http://dx.doi.org/10.5256/f1000research.10491.d148751

Data obtained from Surveillance Research Program of the Division of Cancer Control and Population Sciences, National Cancer Institute, available at: http://seer.cancer.gov/seerstat

Dataset 5. Transformation of raw data in Datasets 2-4 into summary statistics used in the figures and analyses and in Table 1 and 2

http://dx.doi.org/10.5256/f1000research.10491.d148752 


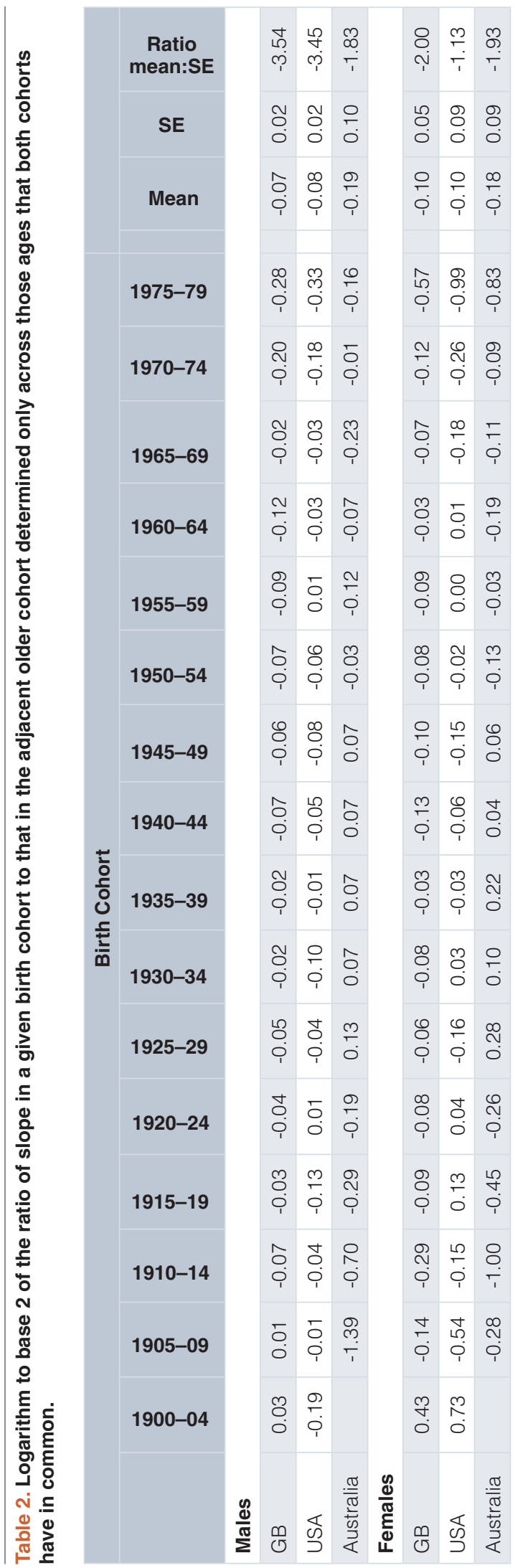


Dataset 6. Summary data for Figure 2, age-specific acceleration of melanoma in different time periods and different countries

http://dx.doi.org/10.5256/f1000research.10491.d148753

\section{Discussion}

We analysed the incidence of malignant melanoma in 6 separate datasets representing males and females from Great Britain, the United States, and Australia, locations with large differences in ambient solar ultraviolet radiation, which is regarded as a major aetiological factor in the disease. Because the incidence of melanoma has tended to increase over time, we calculated the patterns of incidence separately for 17 successive 5-year birth cohorts between 1895 and 1979 in each of the 6 datasets.

In our analysis, we calculated the age-specific incidence separately for each cohort. We also calculated the acceleration of cancer incidence with age for each cohort, in which acceleration is the rate of increase in incidence with age described by the slope of the log incidence $v s$ log age plots.

The tendency over the cohorts has been for incidence to increase and acceleration to decline over time. Figure 1 summarizes the incidence patterns, in which the higher position of the curves with the passing of time expresses the rise in incidence. In that figure, one can also see a tendency for the slope to decline with the passing of time, which corresponds to a decline in acceleration. Figure 2 and Table 2 provide a more detailed summary of the way in which acceleration has tended to decline with the passing of time. The variation between sexes and between countries is clear but unexplained.

It is evident that observed incidence data on melanoma over time are subject to the influence of many factors that include period effects and cohort effects.

Period effects can be regarded as resulting from external factors that affect equally all age groups at a particular calendar time and could be a consequence of economic, environmental or social factors; for example, depletion of the ozone layer resulting in higher levels of ambient ultraviolet radiation. Also, methodological changes in outcome definitions, classifications, or method of data collection, such as increased surveillance, early detection and changes in diagnostic criteria, could also lead to period effects in data.

Cohort effects, on the other hand, result from the unique experience/exposure of a particular group, or cohort, of subjects as they move across time leading to differences in the risk of outcome based on birth year. For example, following the widespread introduction of sunbeds for cosmetic tanning in the 1980s and their popularity amongst younger people, it would be expected that cohorts born after 1960 would be greater users of this form of UV exposure than cohorts born in earlier years. Some factors may influence periods or cohorts depending on their effects, such as educational awareness and prevention campaigns that act at particular times (periods) but may be targeted to certain age groups (cohorts).

The most interesting trend in the data concerns the tendency over time for incidence to rise and acceleration to decline (Figure 1 and Figure 2). In other cancers, various genetic and environmental perturbations cause a similar pattern of rising incidence and declining acceleration ${ }^{8,14-16}$. In some of those cases, the rise in incidence and decline in acceleration appears to follow from abrogation of one or more of the normal genetic or physiological restraining processes that protect against cancer.

In the patterns of melanoma incidence that we observed, it is not clear if the observed rise in incidence and decline in acceleration over time arose from a similar abrogation of a normally restraining genetic or physiological process, perhaps as a consequence of changes in behaviour, education, diagnosis, environment or other common modulators of observed cancer incidence. As further understanding of environmental, genetic and physiological causes of melanoma develops, it will be interesting to determine how changes in particular causes relate to the changing patterns of incidence over time.

\section{Data availability}

Dataset 1. Summary data for Figure 1, age-specific incidence of melanoma in different time periods and different countries. doi, 10.5256/f1000research.10491.d148748 ${ }^{17}$

Dataset 2. Raw age-specific incidence data for Australia for different age groups in different years. Data obtained from Australian Institute of Health and Welfare (AIHW) 2016, Australian Cancer Incidence and Mortality (ACIM) books: Melanoma of the skin, Canberra: AIHW. Available at http://www.aihw.gov.au/ acim-books. doi, 10.5256/f1000research.10491.d148749 ${ }^{18}$

Dataset 3. Raw age-specific incidence data for Great Britain for different age groups in different years. Data obtained from (1) Office for National Statistics, Cancer Registration Statistics, England, available at http://www.ons.gov.uk/peoplepopulation andcommunity/healthandsocialcare/conditionsanddiseases/datasets/cancerregistrationstatisticscancerregistrationstatisticsengland, (2) Welsh Cancer Intelligence and Surveillance Unit, Cancer in Wales, available at: http://www.wcisu.wales.nhs.uk/cancer-inwales-1, and (3) Information and Statistics Division Scotland, Cancer Statistics, available at: http://www.isdscotland.org/Health-Topics/ Cancer/Cancer-Statistics/Skin/. doi, 10.5256/f1000research.10491. d148750 ${ }^{19}$

Dataset 4. Raw age-specific incidence data for USA for different age groups in different years. Data obtained from Surveillance Research Program of the Division of Cancer Control and Population Sciences, National Cancer Institute, available at: http://seer. cancer.gov/seerstat. doi, 10.5256/f1000research.10491.d14875120 
Dataset 5. Transformation of raw data in Dataset 2Dataset 4 into summary statistics used in the figures and analyses and in Table 1 and Table 2. doi, 10.5256/f1000research.10491. d148752 2

Dataset 6. Summary data for Figure 2, age-specific acceleration of melanoma in different time periods and different countries. doi, 10.5256/f1000research.10491.d14875322

\section{Author contributions}

BLD initiated the project, collected the data from public databases, did the analyses, and contributed to writing the manuscript.
SAF contributed to the design of the analyses, the framing of the work in terms of age-specific acceleration, and the writing of the manuscript.

\section{Competing interests}

No competing interests were disclosed.

\section{Grant information}

This work was supported by National Science Foundation (USA) grant DEB-1251035 to SAF.

The funders had no role in study design, data collection and analysis, decision to publish, or preparation of the manuscript.
1. Erdmann F, Lortet-Tieulent J, Schüz J, et al.: International trends in the incidence of malignant melanoma 1953-2008--are recent generations at higher or lower risk? Int J Cancer. 2013; 132(2): 385-400. PubMed Abstract | Publisher Full Text

2. Dennis LK: Analysis of the melanoma epidemic, both apparent and real: data from the 1973 through 1994 surveillance, epidemiology, and end results program registry. Arch Dermatol. 1999; 135(3): 275-80. PubMed Abstract | Publisher Full Text

3. de Vries E, Coebergh JW: Cutaneous malignant melanoma in Europe. Eur J Cancer. 2004; 40(16): 2355-66. PubMled Abstract | Publisher Full Tex

4. Doll R: The age distribution of cancer: implications for models of carcinogenesis. J Roy Stat Soc: Series A (General). 1971; 134(2): 133-166. Publisher Full Text

5. Cook PJ, Doll R, Fellingham SA: A mathematical model for the age distribution of cancer in man. Int $J$ Cancer. 1969; 4(1): 93-112. PubMed Abstract | Publisher Full Text

6. Moolgavkar SH: Commentary: Fifty years of the multistage model: remarks on a landmark paper. Int J Epidemiol. 2004; 33(6): 1182-1183. PubMed Abstract | Publisher Full Text

7. Frank SA: Age-specific acceleration of cancer. Curr Biol. 2004; 14(3): 242-246. PubMed Abstract | Publisher Full Text

8. Frank SA: Dynamics of Cancer: Incidence, Inheritance, and Evolution. Princeton and Oxford: Princeton University Press: 2007. PubMed Abstract

9. Office for National Statistics: Cancer Registration Statistics, England. Reference Source

10. Welsh Cancer Intelligence and Surveillance Unit: Cancer in Wales Reference Source

11. Information and Statistics Division Scotland: Cancer Statistics. Reference Source

12. Surveillance Research Program of the Division of Cancer Control and
Population Sciences. National Cancer Institute. Reference Source

13. Australian Institute of Health and Welfare (AIHW): Australian Cancer Incidence and Mortality (ACIM) books: Melanoma of the skin. Canberra: AlHW; 2016. Reference Source

14. Frank SA: Age-specific incidence of inherited versus sporadic cancers: a test of the multistage theory of carcinogenesis. Proc Natl Acad Sci U S A. 2005; 102(4): 1071-1075.

PubMed Abstract | Publisher Full Text | Free Full Text

15. Ashley DJ: The two "hit" and multiple "hit" theories of carcinogenesis. $\mathrm{Br} J$ Cancer. 1969; 23(2): 313-328.

PubMed Abstract | Publisher Full Text | Free Full Text

16. Knudson AG Jr: Mutation and cancer: statistical study of retinoblastoma Proc Natl Acad Sci U S A. 1971; 68(4): 820-823. PubMed Abstract | Publisher Full Text | Free Full Text

17. Diffey BL, Frank SA: Dataset 1 in: Age-specific acceleration in malignant melanoma. F1000Research. 2017. Data Source

18. Diffey BL, Frank SA: Dataset 2 in: Age-specific acceleration in malignant melanoma. F1000Research. 2017. Data Source

19. Diffey BL, Frank SA: Dataset 3 in: Age-specific acceleration in malignant melanoma. F1000Research. 2017. Data Source

20. Diffey BL, Frank SA: Dataset 4 in: Age-specific acceleration in malignant melanoma. F1000Research. 2017. Data Source

21. Diffey BL, Frank SA: Dataset $\mathbf{5}$ in: Age-specific acceleration in malignant melanoma. F1000Research. 2017. Data Source

22. Diffey BL, Frank SA: Dataset 6 in: Age-specific acceleration in malignant melanoma. F1000Research. 2017 Data Source 


\section{Open Peer Review}

\section{Current Peer Review Status:}

\section{Version 2}

Reviewer Report 30 March 2017

https://doi.org/10.5256/f1000research.11884.r21403

(C) 2017 Young A. This is an open access peer review report distributed under the terms of the Creative Commons Attribution License, which permits unrestricted use, distribution, and reproduction in any medium, provided the original work is properly cited.

\section{Antony Young}

St John's Institute of Dermatology, King's College London, London, UK

I am happy with the revision and hope the paper stimulates research into possible reasons/mechanisms for the observations.

Competing Interests: No competing interests were disclosed.

I confirm that I have read this submission and believe that I have an appropriate level of expertise to confirm that it is of an acceptable scientific standard.

Reviewer Report 24 February 2017

https://doi.org/10.5256/f1000research.11884.r20505

(C) 2017 Noble R. This is an open access peer review report distributed under the terms of the Creative Commons Attribution License, which permits unrestricted use, distribution, and reproduction in any medium, provided the original work is properly cited.

\section{Robert J. Noble}

Department of Biosystems Science and Engineering, ETH Zurich, Basel, Switzerland

The authors have addressed concerns raised in my review of the previous version, and I have no further comments.

Competing Interests: No competing interests were disclosed.

I confirm that I have read this submission and believe that I have an appropriate level of expertise to confirm that it is of an acceptable scientific standard. 


\section{Version 1}

Reviewer Report 17 February 2017

\section{https://doi.org/10.5256/f1000research.11306.r19972}

(C) 2017 Noble R. This is an open access peer review report distributed under the terms of the Creative Commons Attribution License, which permits unrestricted use, distribution, and reproduction in any medium, provided the original work is properly cited.

\section{Robert J. Noble}

Department of Biosystems Science and Engineering, ETH Zurich, Basel, Switzerland

This well presented study describes an interesting trend in melanoma incidence in three industrialised nations and proposes an explanatory hypothesis. The major caveat is that, as the authors acknowledge, this trend could be due to any number of cohort effects (i.e. changing environmental and social factors that unequally affect different age groups and cohorts). The decrease in acceleration of melanoma incidence could, for example, be due to changes in skin cancer prevention campaigns, foreign travel, fashion, sunbathing behaviour, sunbed use, or frequency of dermatological examination. As the authors do not control for any such factors and provide no evidence for or against any particular hypothesis, they can do no more than speculate about how the observed pattern arose.

Also importantly, it is unclear to me exactly what the authors mean by a "restraining process" or "protective mechanism" that might have become less effective over time, nor how such a process might be affected by "a change in environmental exposure patterns" or "more intense environmental challenges". I suspect they mean to suggest that a germline mutation that inactivates a tumour suppressor gene has become more prevalent due to natural selection or genetic drift, but I am unsure if this interpretation is correct. In any case, it would be useful to have more details of the hypothesis and its testable predictions. Would the authors expect to see a similar trend in other cancer types? Why might some countries be more affected than others? And why might men and women be affected differently?

The study might also benefit from using a mathematical model (as, for example, in reference 14) to estimate how much decrease in prevalence of the protective mechanism would be necessary to explain the observed trends.

Competing Interests: No competing interests were disclosed.

\section{I confirm that I have read this submission and believe that I have an appropriate level of expertise to confirm that it is of an acceptable scientific standard, however I have significant reservations, as outlined above.}

Author Response ( F1000Research Advisory Board Member ) 21 Feb 2017

Steven Frank, Department of Ecology \& Evolutionary Biology, University of California, 
Irvine, USA

We thank Robert Noble for his comments and helpful criticisms.

The main comment in Robert Noble's review suggested that we add more detail about our mechanistic hypothesis. The other referee, Antony Young, made the opposite comment, suggesting that we delete our discussion of mechanism because it is too speculative.

After considering these opposing suggestions, we decided to delete our previous discussion of possible mechanisms that could explain the observed rise in incidence and decline in acceleration. The entire focus of our analysis and presentation concerned the patterns of incidence over time in the available data. We have no profound insight into the possible mechanistic causes of the interesting patterns that we observed. Thus, we have chosen in the revision to keep the focus on the data and the patterns that emerged from our analysis.

We remain very interested in the puzzle that has emerged from our analysis. However, we now think it best to defer any mechanistic discussions and model development until we have a more compelling argument that could be published as a follow up study to the data in this article.

\section{Competing Interests: None}

Reviewer Report 13 February 2017

\section{https://doi.org/10.5256/f1000research.11306.r20144}

(C) 2017 Young A. This is an open access peer review report distributed under the terms of the Creative Commons Attribution License, which permits unrestricted use, distribution, and reproduction in any medium, provided the original work is properly cited.

\section{Antony Young}

St John's Institute of Dermatology, King's College London, London, UK

I found this paper very interesting but hard to follow at times. The $2^{\text {nd }}$ column of the discussion seems to be at bit contradictory. The authors give possible mechanistic explanations for their observations then draw attention to the many uncertainties in the final paragraph. My own view is that these uncertainties are so large that it is too speculative to comment on biological mechanisms. The sex and country differences are apparent in the figures but it would be interesting to comment on these in the discussion. Can anything be explained by aggressive public health campaigns in Australia?

Specific points

1. What is the scaling of the $x$ axis of Figure 1? 
2. Different colour codes are used in Figures 1 and 2 which I found confusing

3. Are educational and prevention campaigns period effects? I would have thought that they are cohort effects, because the age group that they affect is likely to be important

4. Should sunscreens be mentioned? Their possible role in melanoma has been analyzed in several studies

5. Can anything be deduced about latitude effects?

Competing Interests: No competing interests were disclosed.

\section{I confirm that I have read this submission and believe that I have an appropriate level of expertise to confirm that it is of an acceptable scientific standard, however I have significant reservations, as outlined above.}

Author Response ( F1000Research Advisory Board Member ) 21 Feb 2017

Steven Frank, Department of Ecology \& Evolutionary Biology, University of California, Irvine, USA

We thank Antony Young for his comments and helpful criticisms.

In response to the criticism that our discussion of mechanism raised too many uncertainties, we have deleted those paragraphs. In the revision, we replace that part of the discussion with a brief summary of the key result: the observed rise in incidence and decline in acceleration over time. We then add a couple of sentences about the range of factors that may be involved and how those factors may act via the normal genetic and physiological processes that protect against cancer, by analogy with other cancers for which there is more genetic and physiological information about the relation between mechanism and patterns of incidence.

With regard to specific comments:

We added a description of the scaling of axes to the legend of Figure 1.

We clarified that education and prevention campaigns could act as either period or cohort effects, depending on the targeting of age groups.

The suggestions about public health campaigns in Australia, sunscreens, and latitude are all interesting possibilities. We do not have sufficient data or insight to say anything compelling about those issues, so we have not added any new analyses or discussion to the revision.

Competing Interests: None 
The benefits of publishing with F1000Research:

- Your article is published within days, with no editorial bias

- You can publish traditional articles, null/negative results, case reports, data notes and more

- The peer review process is transparent and collaborative

- Your article is indexed in PubMed after passing peer review

- Dedicated customer support at every stage

For pre-submission enquiries, contact research@f1000.com 